\title{
Laser Surface Alloying of Various Engineering Alloys for Sliding Wear and Corrosion Resistance
}

\author{
Chi Tat KWOK ${ }^{* 1}$ and Po Kee WONG ${ }^{1}$ \\ ${ }^{* 1}$ Department of Electromechanical Engineering, Room N409, Choi Kai Yau Building, Faculty of \\ Science and Technology, University of Macau, Taipa, Macau \\ *Email:fstctk@umac.mo
}

\begin{abstract}
Laser surface alloying (LSA) of four different substrate alloys, including mild steel (G10500), austenitic stainless steel (S30400), aluminum alloy (A97075) and brass (C26000), with FeCrMoMnWCB powder (Nanosteel SHS717) was attempted. LSA was conducted in a two-step process: the powder was preplaced on the surface of the substrate by flame spraying and the preplaced layer was subsequently remelted using a $2.5-\mathrm{kW}$ CW Nd:YAG laser beam. The microstructures, sliding wear and corrosion behavior were studied by scanning electron microscopy, and X-ray diffractometry, pin-on-disc wear test and potentiodynamic polarization technique. For laser-alloyed G10500, S30400 and A97075, uniform alloyed layers were obtained by LSA but some cracks were found in laser-alloyed A97075. On the other hand, a non-uniform alloyed layer was observed on the surface of C26000 due to its high reflectivity and ball-up effect. For G10500 and S30400, the alloyed layers consisted of ferritic/austenitic iron-based matrix reinforced with the boro-carbides and their hardness increased to about 220 and 250 HV respectively. For A97075, the alloyed layer consisted of iron aluminides as the major phases and its hardness increased up to $450 \mathrm{HV}$. The sliding wear resistance of laser-alloyed S30400 and A97075 was higher than that of the substrates due to the presence of hard phases such as iron aluminide and boro-carbides, and solid solution hardened matrix. All of the laser-alloyed specimens showed no passivation in $3.5 \% \mathrm{NaCl}$ solution at $23{ }^{\circ} \mathrm{C}$. Except laser-alloyed C26000, the corrosion resistance of laser-alloyed G10500, S30400 and A97075 in $3.5 \% \mathrm{NaCl}$ solution was deteriorated after LSA as evidenced by the increase in corrosion current density compared with the as-received specimens due to the existence of the phase boundaries of boro-carbides and iron aluminides as the active phases for corrosion attack. Among the laser-alloyed specimens, laser-alloyed S30400 possessed the highest wear and corrosion resistance.
\end{abstract}

DOI: 10.2961/jlmn.2010.01.0019

Keywords: Laser surface alloying, microstructure, wear, corrosion

\section{Introduction}

Nowadays, laser surface alloying (LSA) has been widely applied in remanufacturing of defective engineering components due to high precision, localized thermal action and power controllability of laser. It utilizes high power density from the focused laser beam to melt pre-deposited coatings and a portion of the underlying substrate to form an alloyed zone for improving wear, corrosion and oxidation resistance [1]. Since the melting occurs in a very short time and only at the surface, the bulk of the substrate remains cool, thus serves as a heat sink. Large temperature gradients exist across the boundary between the melted surface region and the underlying solid substrate, resulting in rapid self-quenching and resolidification. Owing to this, the advantages of using laser for surface treatment include: formation of a non-equilibrium or amorphous phase, homogenization and refinement of microstructure, formation of a metallurgical bond between the surface layer and the substrate, and a small heat-affected zone [2]. The state-ofthe-art LSA technique is applicable to a wide range of metals for improving their functional properties [3-4]. By LSA, introduction of alloying elements or compounds not only changes the local visual appearance of the base metal (for marking) but also modifies its chemical composition, microstructure, corrosion and wear resistance [3-4]. Dispersing tiny hard phases in a matrix through LSA offers a possible route for developing new alloys for obtaining desired properties [5-10]. For instance, the powder mix on the surface of plain carbon steel containing $\mathrm{Cr} / \mathrm{Ni}$ and carbides/borides is for corrosion resistance and erosion and abrasion resistance respectively [11]. Moreover, the hard phases such as silicon carbide, boro-carbides, iron and nickel aluminides can be introduced by LSA of $\mathrm{SiC}$ on stainless steel S30400 [5] and mild steel G10400 [6], $\mathrm{NiCrSiB}$ and AlSiFe on mild steel G10500 [7-8], NiCrSiB on aluminum alloy A97075 [9] and $\mathrm{NiCrSiB}$ on brass [10] for enhancing surface hardness, wear, cavitation erosion and corrosion resistance of the substrates.

The aim of present study is to investigate the possibility of fabricating alloyed layers on various substrates including steels, aluminum and copper alloys with a hardfacing alloy FeCrMoMnWCB for wear and corrosion resistance. FeCrMoMnWCB is chosen because carbon and boron can form hard phases and $\mathrm{Cr}$ and Mo can enhance corrosion resistance. 


\section{Experimental details}

LSA of four different substrate alloys (in form of cylindrial bar with diameter of $18.8 \mathrm{~mm}$ and thickness of 10 $\mathrm{mm}$ ), including mild steel (G10500), austenitic stainless steel (S30400), aluminum alloy (A97075) and brass (C26000), with FeCrMoMnWCB powder (SHS717, commercially obtained from Nanosteel Co.) was attempted. The various substrate alloys are selected because of their widespread applications in industry [12], different reflectivity to Nd:YAG laser [13] and different mutual solubility [14] with the FeCrMoMnWCB alloy. The chemical compositions of the alloys and the powder are shown in Table 1. The particle size of the powder was in the range of 15 - 53 $\mu \mathrm{m}$. LSA was conducted in a two-step process: the powder was preplaced on the surface of the substrate by flame spraying and the preplaced layer with nominal thickness of $0.2 \mathrm{~mm}$ was subsequently remelted using a $2.5-\mathrm{kW}$ CW Nd:YAG laser beam. Flame spraying of FeCrMoMnWCB powder on the substrate alloys was achieved using an oxyacetylene flame spraying gun (Shanghai Welding and Cutting Tool Works, Model SPH-2/h) as shown in Fig. 1. The flame used is neutral. The distance between the nozzle of the gun and the specimens was kept at $80 \mathrm{~mm}$. In order to determine the thickness of the preplaced layers, transverse cross-sections were made and then observed by an optical microscope. Average thickness was obtained from three locations of the preplaced layers. Subsequent laser surface melting of the layers was carried out in the assprayed condition. Laser power of $1.2 \mathrm{~kW}$, a beam size of 4 $\mathrm{mm}$ in diameter and a scanning speed of $25 \mathrm{~mm} / \mathrm{s}$ were used. Argon flowing at $20 \mathrm{l} / \mathrm{min}$. was used as the shielding gas. The melt surface was achieved by overlapping the melt tracks. The dilution ratio $(D R)$ of the laser-alloyed layer is defined as follows:

$$
D R=1-\frac{t}{D}
$$

where $t$ is the thickness of preplaced layer and $D$ is the melt depth. According to this definition, the higher is the value of $D R$, the higher is the degree of dilution. The details of the laser parameters are given in Table 2. The microstructures and hardness of the alloyed layers were studied by scanning electron microscopy (SEM), X-ray diffractometry (XRD) and microhardness test at a load of $200 \mathrm{~g}$ and a loading time of $15 \mathrm{~s}$.

Sliding wear test of the alloys was conducted using a pin-on-disc tribometer. The laser-alloyed and as-received (untreated) specimens were forced to slide against a counterface $\mathrm{SiC}$ disc in air under unlubricated condition at a sliding speed of $31 \mathrm{~km} / \mathrm{h}$ and a load of $10 \mathrm{~N}$. The test duration was 10 hours. The weight loss $\Delta W$ (in g) of the specimen in time $t$ (in hour) was recorded by an electronic balance of $0.1 \mathrm{mg}$ precision and the volume loss $\Delta V$ (in $\mathrm{mm}^{3}$ ) was calculated by the following equations:

$$
\Delta V=1000 \Delta W / \rho
$$

where $\rho$ is the density of the alloys in $\mathrm{g} / \mathrm{cm}^{3}$. Hence the plot of cumulative volume loss against time was obtained. The wear rate $W$ (in $\mathrm{mm}^{3} / \mathrm{h}$ ) and wear resistance $R$ (in $\mathrm{h} / \mathrm{mm}^{3}$ ) are defined as:

$$
\begin{aligned}
& W=\Delta V / t \\
& R=1 / W
\end{aligned}
$$

The worn surfaces of the selected specimens after sliding wear test were then characterized by SEM.

To investigate electrochemical corrosion behavior, the specimens were embedded in cold-curing epoxy resin, exposing a surface area of $1 \mathrm{~cm}^{2}$. Potentiodynamic polarization test in $3.5 \% \mathrm{NaCl}$ solution, open to air at $23 \pm 1{ }^{\circ} \mathrm{C}$, was performed using a PAR VersastatII potentiostat according to ASTM Standard G5-92 [15]. All potentials were measured with respect to a saturated calomel electrode (SCE, $0.244 \mathrm{~V}$ versus SHE at $25^{\circ} \mathrm{C}$ ) as the reference electrode. Two parallel graphite rods served as the counter electrode for current measurement. After an initial delay of 5 min., the potential was increased at a rate of $0.167 \mathrm{mV} \mathrm{s}^{-1}$, starting from $200 \mathrm{mV}$ below the open circuit potential. From the polarization curve, the corrosion potential $\left(\mathrm{E}_{\text {corr }}\right)$ and corrosion current density ( $\mathrm{I}_{\text {corr }}$ ) were evaluated by Tafel extrapolation method by software (PowerCORR, V.2.42).

Table 1 Compositions of various alloys and powder.

\begin{tabular}{lcccccccccccccc}
\hline Material & Fe & Cr & Ni & Mn & Al & Cu & Zn & Mg & Mo & W & Zr & Si & B & C \\
\hline G10500 & bal & 0.2 & - & 0.4 & - & 0.9 & - & - & - & - & - & - & - & 0.5 \\
S30400 & bal & 18.4 & 8.7 & - & & & - & - & - & - & - & - & - & 0.08 \\
A97075 & - & 0.2 & - & - & bal & 1.6 & 5.6 & 2.5 & - & - & - & - & - & - \\
C26000 & - & - & - & - & - & bal & 35 & - & - & - & - & - & - & - \\
SHS717 & bal & 21 & - & 3 & - & - & - & - & 5.7 & 7 & 2 & 1.2 & 4 & 1.5 \\
\hline
\end{tabular}

\begin{tabular}{|c|c|c|c|c|}
\hline Specimen & $\begin{array}{l}\text { Depth } \\
\text { alloyed z } \\
D(\mathrm{~mm})\end{array}$ & $\begin{array}{l}\text { of Overlapping } \\
\text { one } O L^{\text {a }}(\%)\end{array}$ & $\begin{array}{l}\text { Dilution } \\
\text { ratio } \\
D R(\%)\end{array}$ & Major phases present \\
\hline LA-G10500 & 0.29 & 50 & 31 & $\alpha-\mathrm{Fe}, \mathrm{Fe}_{23}(\mathrm{BC})_{6}$ \\
\hline LA-S 30400 & 0.25 & 50 & 20 & $\gamma-\mathrm{Fe}, \mathrm{Fe}_{23}(\mathrm{BC})_{6}$ \\
\hline LA-A97075 & 0.35 & 50 & 43 & $\mathrm{FeAl}, \mathrm{Fe}_{2} \mathrm{Al}_{5}$ \\
\hline LA-C 26000 & 0.29 & 50 & 31 & $\begin{array}{c}\alpha-\mathrm{Cu}, \alpha-\mathrm{Fe} \\
\mathrm{Fe}_{23}(\mathrm{BC})_{6}\end{array}$ \\
\hline
\end{tabular}

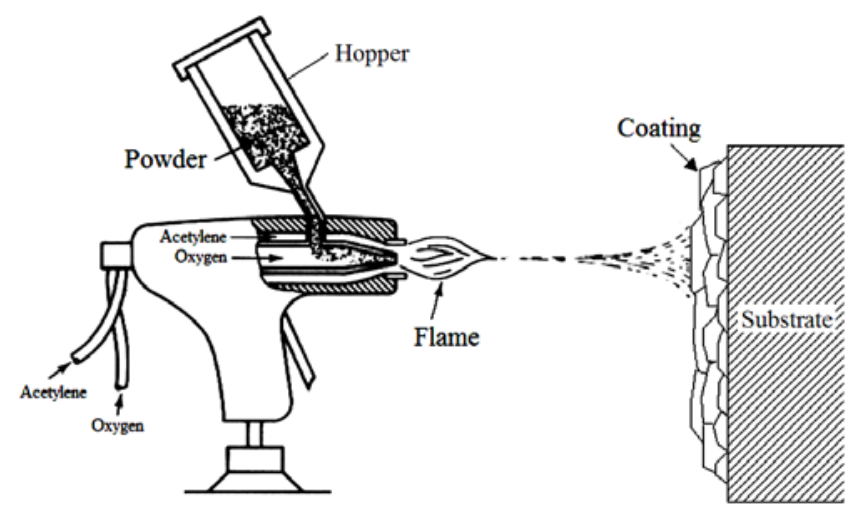

Fig. 1 Schematic diagram of flame spraying.

Table 2 Laser parameters for LSA of various alloys.

\section{Results and discussion}

\subsection{Microstructure analysis}


The cross-sectional view, microstructure, compositional and hardness profiles and XRD spectra of the laseralloyed specimens are shown in Figs. 2 to 6. For laseralloyed G10500, S30400 and A97075 (designated as LAG10500, LA-S30400 and LA-A97075), uniform alloyed layers were obtained by LSA but some cracks were found in LA-A97075. On the other hand, a non-uniform alloyed layer was observed on the surface of C26000 (designated as LA-C26000) due to its high reflectivity and ball-up effect. Fine cellular and dendritic patterns were observed in both LA-G10500 and LA-S30400. From the XRD spectra, LA-G10500 and LA-S30400 consisted of boro-carbides $\left(\mathrm{Fe}_{23}(\mathrm{CB})_{6}\right)$ which were reinforced in the ferritic and austenitic iron-based matrix respectively and their hardness increased to about 220 and $250 \mathrm{HV}$ respectively. For LAA97075, the alloyed layer consisted of needle-shape iron aluminides (FeAl and $\mathrm{Fe}_{2} \mathrm{Al}_{5}$ ) as the major phases (Figs. 3c and $5 \mathrm{c}$ ) and its hardness increased up to $450 \mathrm{HV}$.
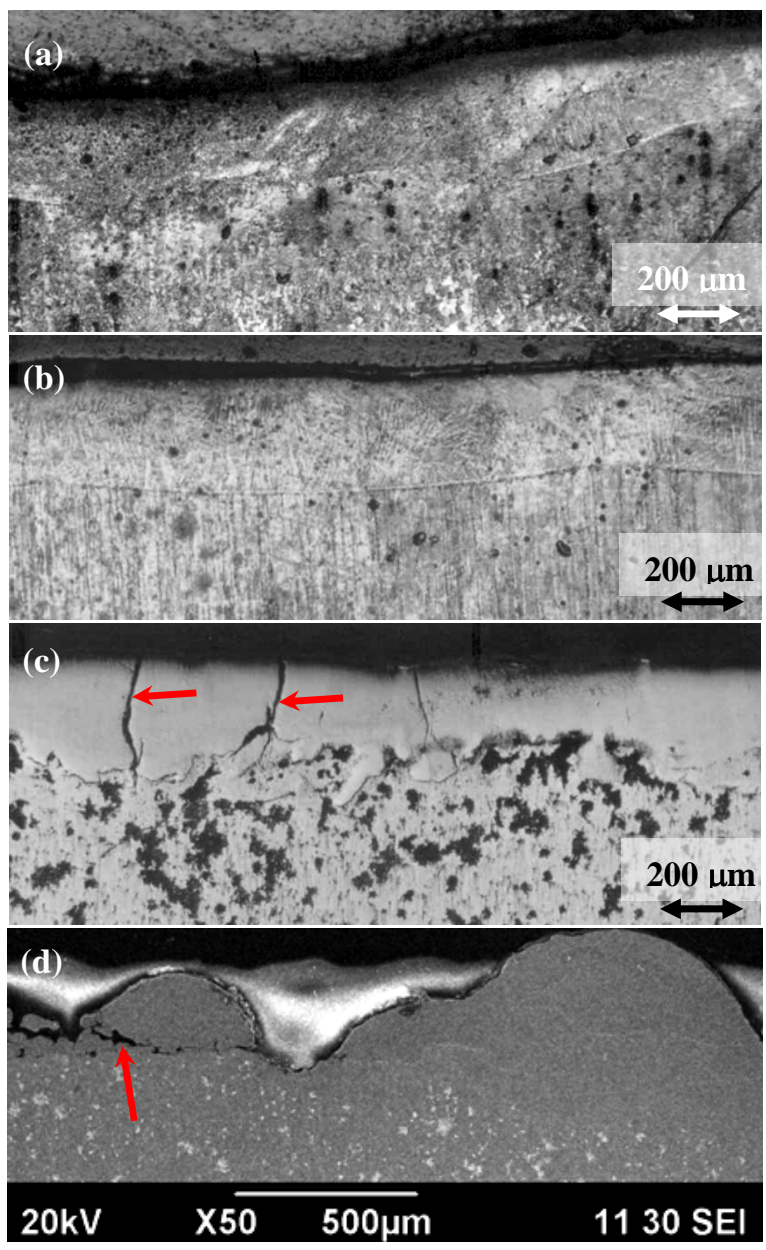

Fig. 2 Cross-sectional view of laser-alloyed specimens (a) G10500, (b) S30400, (c) A97075 and (d) C26000 (the magnifications of all micrographs are the same: 50X).
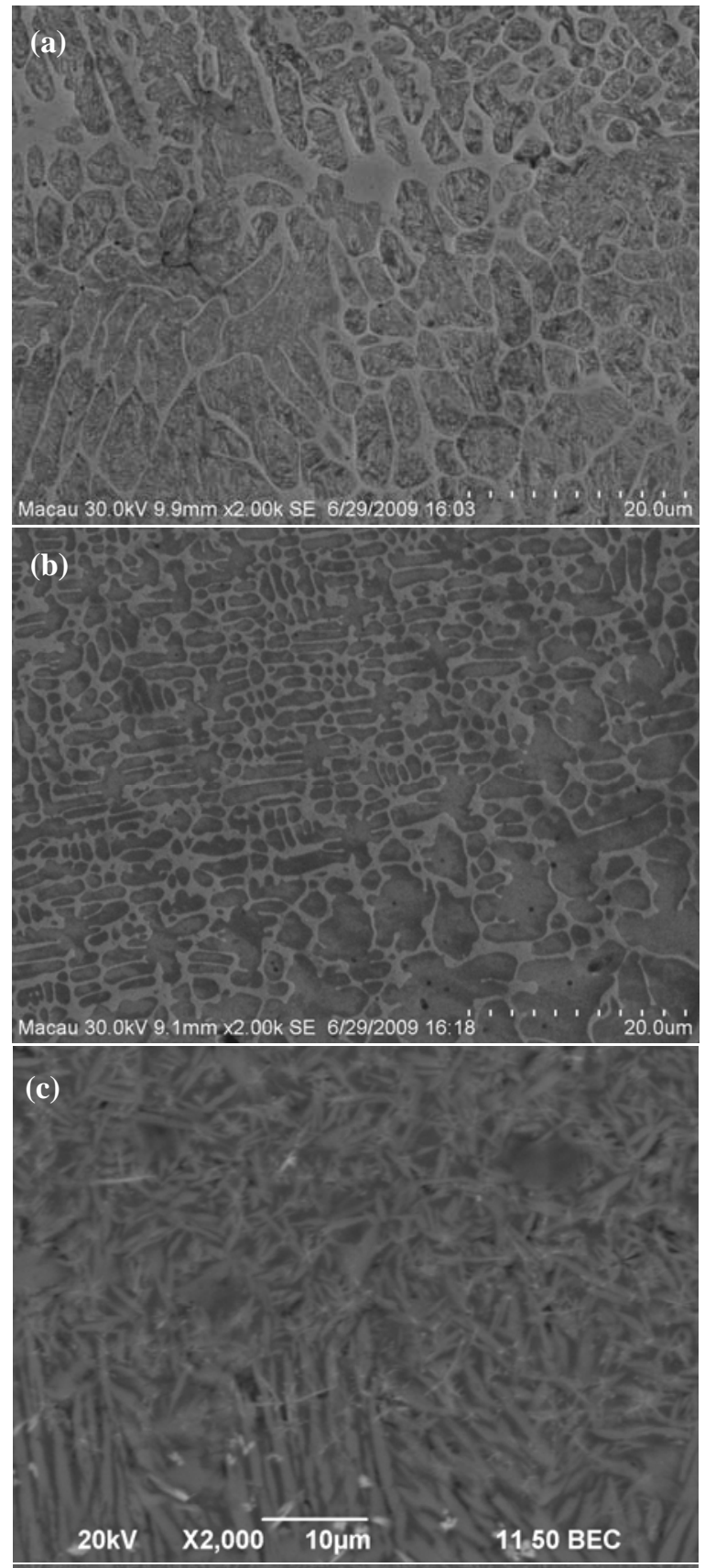

(d)

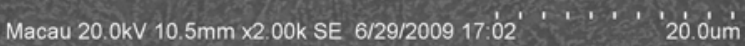

Fig. 3 Microstructure of laser-alloyed specimens (a) G10500, (b) S30400, (c) A97075 and (d) C26000 (the magnifications of all micrographs are the same: $2000 \mathrm{X}$ ). 

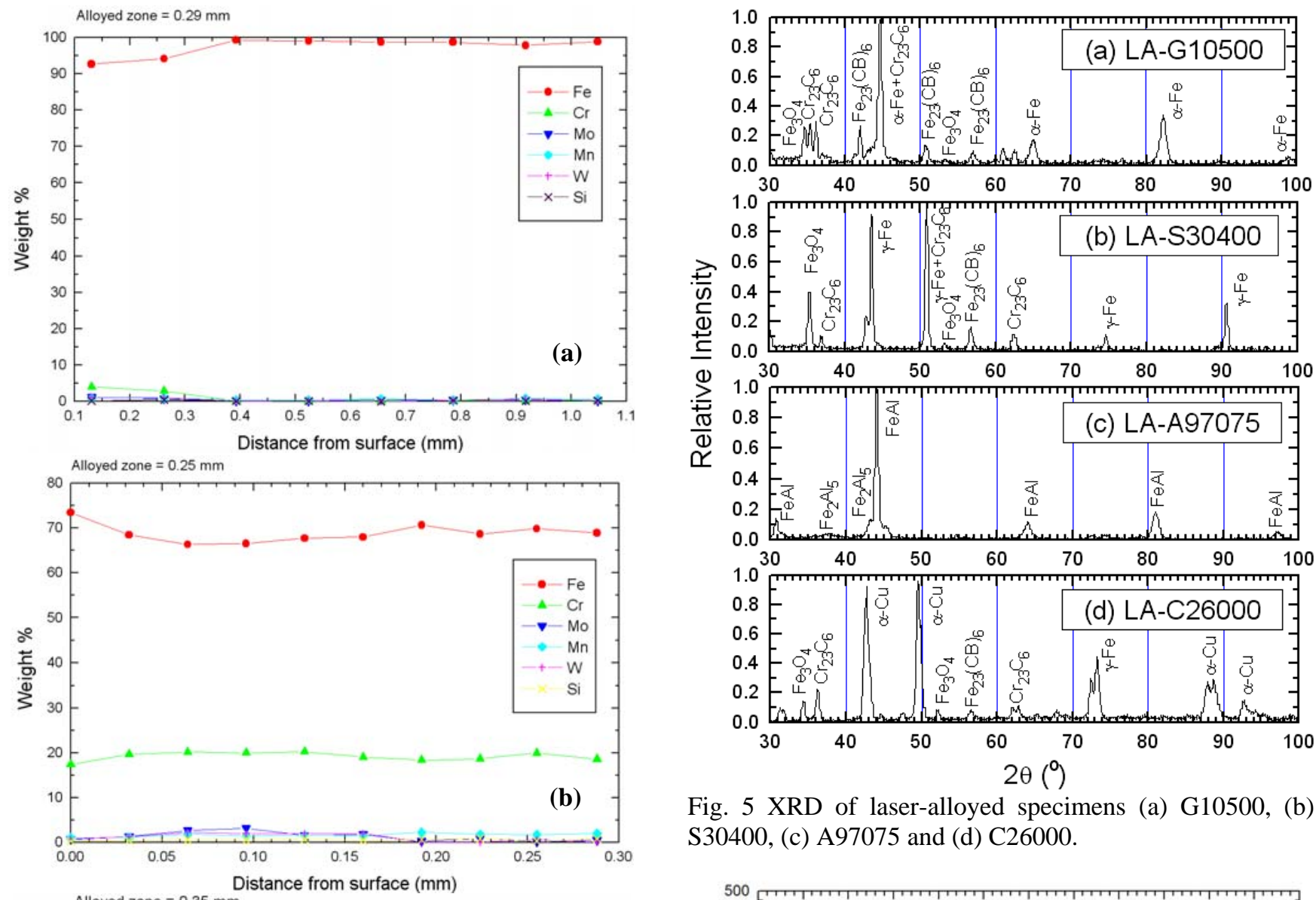

Fig. 5 XRD of laser-alloyed specimens (a) G10500, (b) S30400, (c) A97075 and (d) C26000.
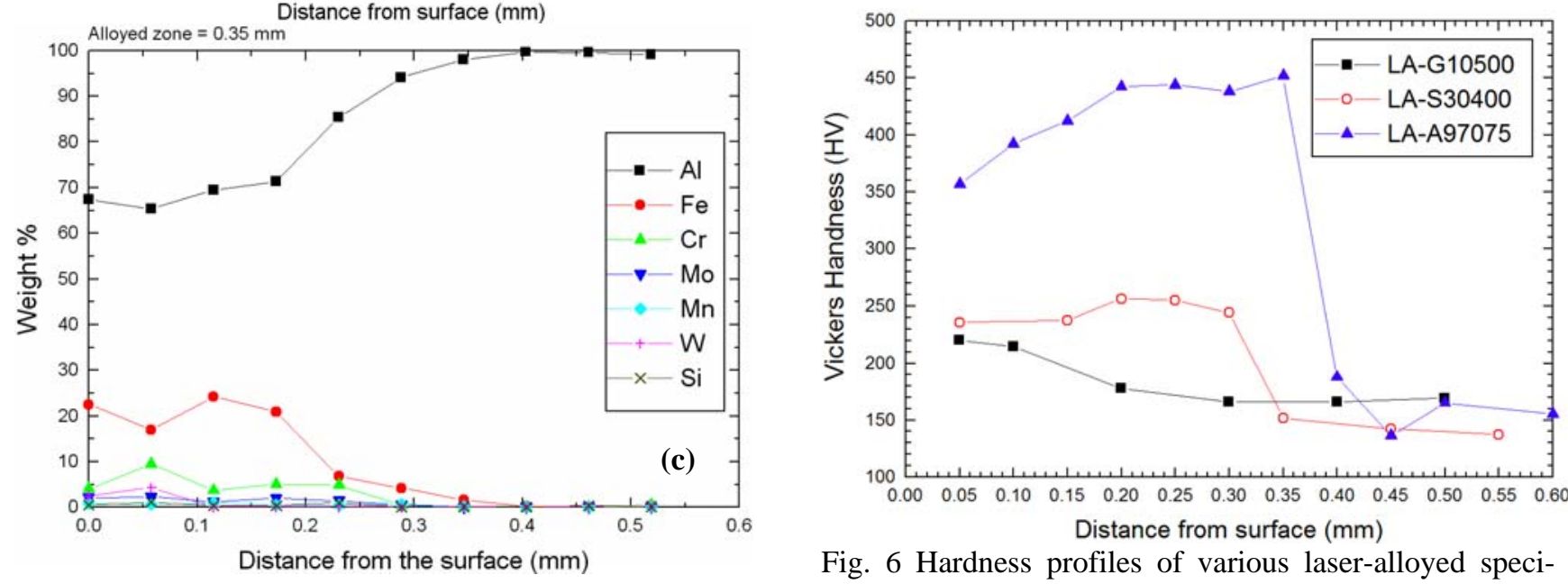

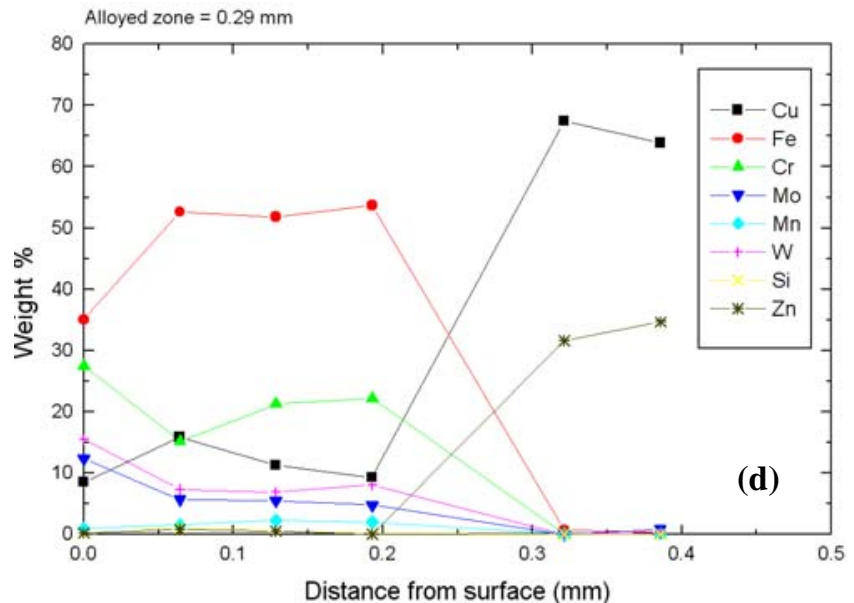

Fig. 4 Compositional profiles of laser-alloyed specimens (a) G10500, (b) S30400, (c) A97075 and (d) C26000.
Fig. 6 Hardness profiles of various laser-alloyed specimens.

\subsection{Wear behavior}

The plots of cumulative volume loss vs time for various laser-alloyed and as-received specimens are shown in Fig. 7. The cumulative volume loss increases with the sliding time or distance. The bar chart of sliding wear resistance $R$ for various specimens after the 10-h wear test is shown in Fig. 8. Among the specimens, the value of $R$ of LA-S30400 is the largest. Whereas the alloyed layer of LA-C26000 was completely worn away for only 30 minutes due to its protrusion and weak bond with substrate resulting in rapid delamination. The ranking of $R$ in descending orders is:

LA-S30400 > LA-G10500 G10500 > LA-A97075 > $\mathrm{S} 30400>\mathrm{C} 26000>\mathrm{A} 97075$

LSA of FeCrMoMnWCB on various substrate alloys significantly improved the hardness and hence the sliding 
wear resistance due to the presence of dispersed hard phases such as boro-carbides and iron aluminides in the solid solution hardened matrix. Compared with the asreceived substrate alloys, the wear resistance of the laseralloyed specimens was increased by 15 and 6 times for LAA97075 and LA-S30400 respectively. However, only a slight increase in wear resistance is observed in LAG10500. The wear resistance of LA-S30400 is higher than LA-A97075 although the hardness of the latter is the highest because of the presence of cracks in the alloyed layer of LA-A97075 resulting in brittle fracture and rapid loss of material.

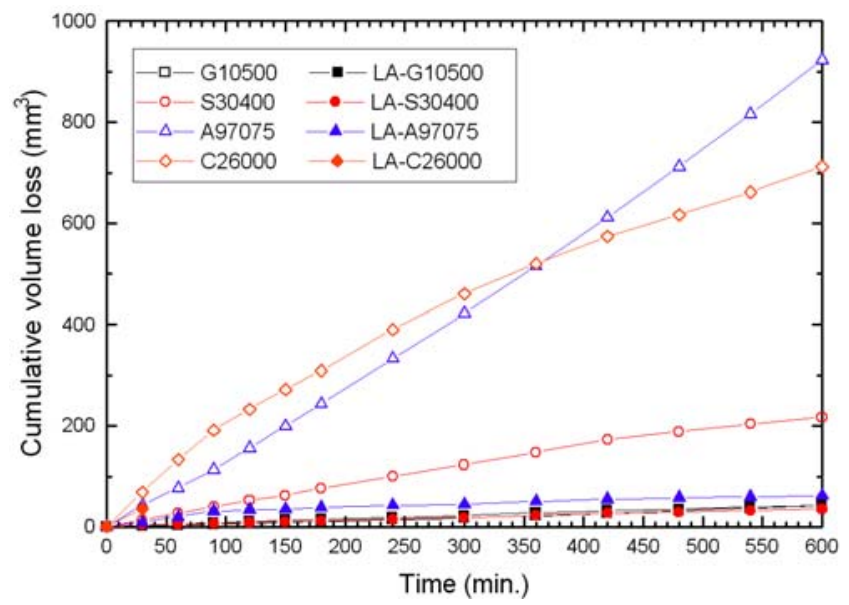

Fig 7 Cumulative volume loss versus time for various alloys before and after LSA.

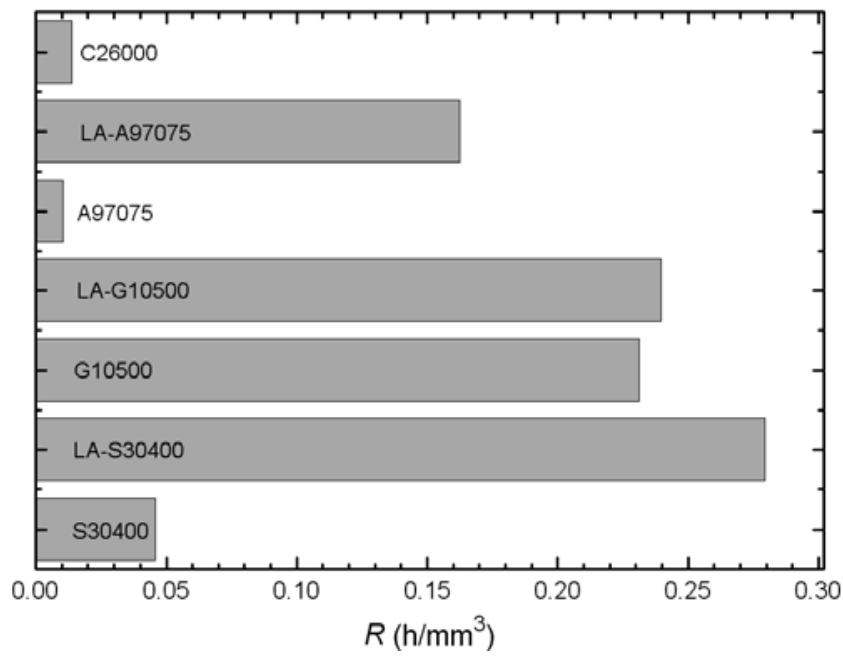

Fig. 8 Sliding wear resistance for various alloys before and after LSA.

Friction is the main factor of mechanical wear when the specimens slide against the ceramic disc. For abrasive wear, the harder disc plastically deforms the softer specimens. The typical SEM micrographs of the worn surfaces of LAS30400 and LA-A97075 are shown in Fig. 9. The laseralloyed specimens and their oxides are removed by forming microchips (indicated by the arrows in Fig. 9), thereby producing scratches on the softer surface. The presence of scratches is due to the action of the ceramic disc. In micro- scale, asperities of the harder surface press into the softer surface, with plastic flow of the softer surface occurring around the harder asperities. Adhesive wear and abrasive wear are the dominant wear mechanisms during sliding which results in metal transfer, film formation and removal, debris generation and cyclic surface deterioration.

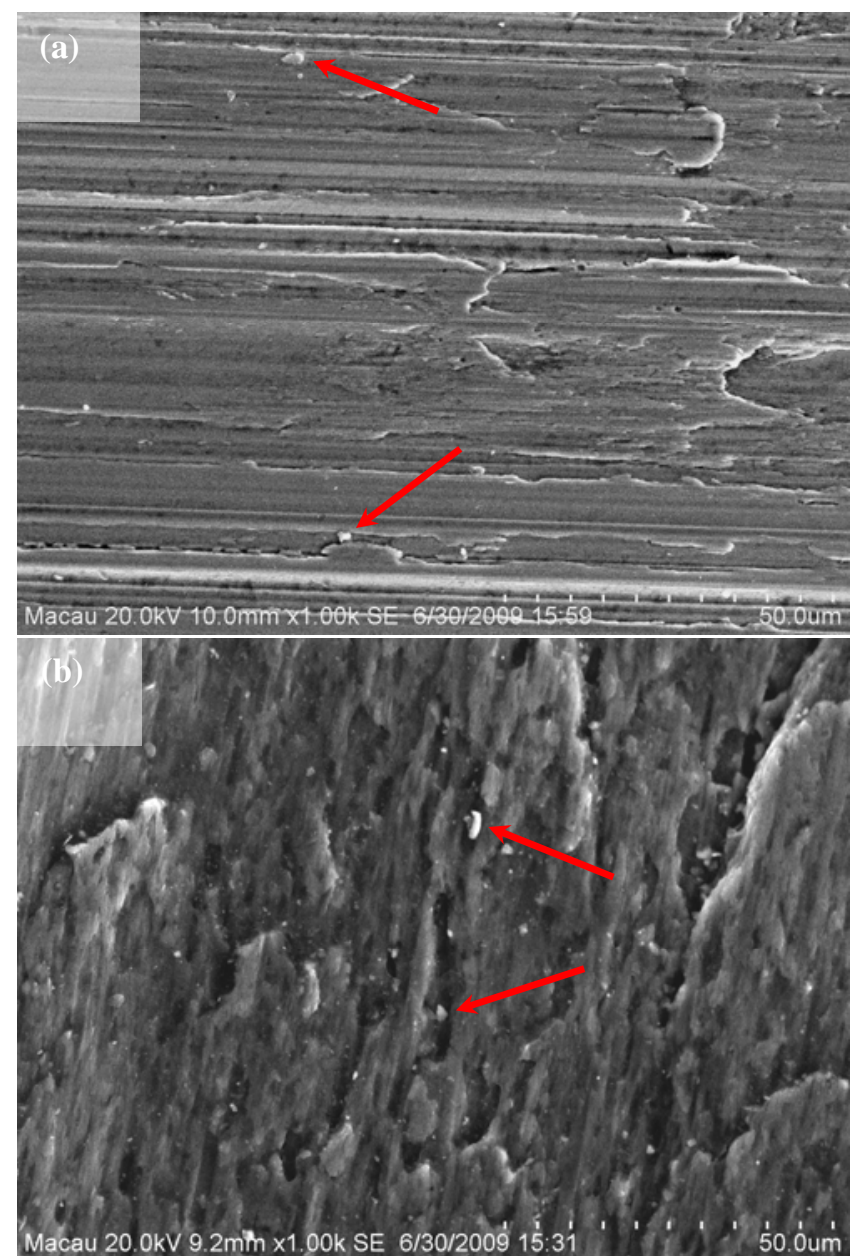

Fig. 9 Worn surfaces of (a) LA-S30400 and (b) LAA97075 (the magnifications of all micrographs are the same: 1000X).

\subsection{Corrosion behavior}

The polarization curves for the laser-alloyed specimens in $3.5 \% \mathrm{NaCl}$ solution (open to air) at $23{ }^{\circ} \mathrm{C}$ are shown in Fig. 10 and the key electrochemical parameters $\left(\mathrm{E}_{\text {corr }}, \mathrm{I}_{\text {corr }}\right.$ and $\left.\mathrm{E}_{\mathrm{pit}}\right)$ for the laser-alloyed and as-received specimens are shown in Table 3. After LSA, the $E_{\text {corr }}$ of S30400 and C26000 shifted in the active direction whereas the $E_{\text {corr }}$ of G10500 and A97075 shifted in the noble direction. This shows the higher thermodynamic stability of LA-G10500 and LA-A97075 in 3.5\% NaCl solution compared with the as-received specimens. The ranking of $\mathrm{E}_{\text {corr }}$ of various specimens in $3.5 \% \mathrm{NaCl}$ solution at $23^{\circ} \mathrm{C}$ is:

S30400 > LA-S30400 > C26000 > LA-C26000 >

LA-G10500 > G10500 > LA-A97075 > A97075

The laser-alloyed specimens including LA-S30400, LA-G10500 and LA-C26000 showed no passivation in 3.5\% $\mathrm{NaCl}$ solution. Except LA-C26000 and LA-G10500, the corrosion resistance of LA-S30400 and LA-A97075 in 
$3.5 \% \mathrm{NaCl}$ solution was deteriorated as evidenced by the increase in $\mathrm{I}_{\text {corr }}$ compared with the as-received specimens due to the existence of the phase boundaries of borocarbides and iron aluminides as the active sites for corrosion attack. The cracks on the alloyed layer of LA-A97075 can allow the $\mathrm{NaCl}$ solution to reach to the underlying substrate thus a galvanic coupling is formed. Since the area of the alloyed layer of LA-A97075 (the cathode) is much larger than that of the underlying substrate (the anode) exposed to the solution, it leads a higher corrosion rate in LAA97075 [16]. Although the discontinuous alloyed layer on C26000 is non-uniform and the underlying brass is partially exposed to the $\mathrm{NaCl}$ solution, the galvanic effect between the alloyed layer (the anode) and the brass substrate (the cathode) is not significant because the cathodic area is smaller than the anodic area. In addition, the mixing of $\mathrm{Cr}$, Mo and $\mathrm{Cu}$ might enhance the corrosion resistance of LAC26000. Among the laser-alloyed specimens, LA-S30400 possessed the highest corrosion resistance.

Among the laser-alloyed specimens, LA-S30400 possesses the highest wear resistance and the noblest $\mathrm{E}_{\text {corr }}$ and the lowest $\mathrm{I}_{\text {corr }}$, indicating that it is a good candidate to be used in tribological and chloride-containing environments.

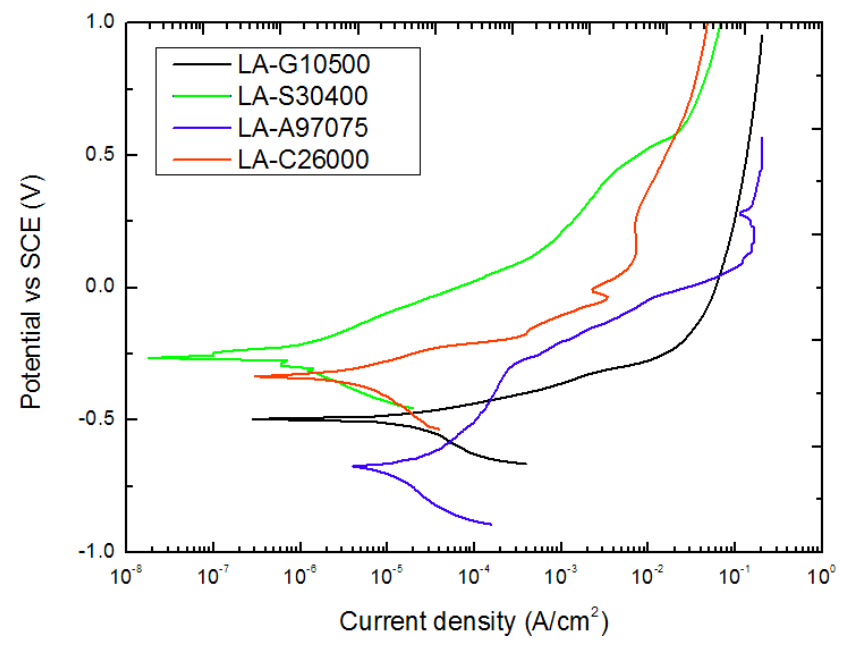

Fig. 10 Polarization curves for various alloys after LSA.

Table 3 Corrosion parameters of various alloys before and after LSA in $3.5 \% \mathrm{NaCl}$ solution at $23^{\circ} \mathrm{C}$.

\begin{tabular}{|c|c|c|c|}
\hline Specimens & $E_{\text {corr }}(\mathrm{V})$ & $\mathrm{I}_{\text {corr }}\left(\mu \mathrm{A} / \mathrm{cm}^{2}\right)$ & $\mathrm{E}_{\text {pit }}(\mathrm{V})$ \\
\hline G10500 & -0.663 & 8.47 & active \\
\hline S30400 & -0.224 & 0.02 & 0.267 \\
\hline A97075 & -0.819 & 0.31 & active \\
\hline C26000 & -0.270 & 33.9 & -0.144 \\
\hline LA-G10500 & -0.495 & 0.50 & active \\
\hline LA-S30400 & -0.260 & 0.04 & active \\
\hline LA-A97075 & -0.676 & 4.63 & active \\
\hline LA-C26000 & -0.335 & 0.50 & active \\
\hline
\end{tabular}

\section{Conclusions}

1. For laser-alloyed G10500 and S30400, the alloyed layers consisted of boro-carbides reinforced in the ferritic and austenitic iron-based matrix respectively and their hardness increased to about 220 and $250 \mathrm{HV}$ respectively.
2. For LA-A97075, the alloyed layer consisted of needleshape iron aluminides as the major phase and was presence of cracks. Its hardness increased up to 450 HV.

3. The ranking of sliding wear resistance of the specimens in descending order is: LA-S30400 > LA$\mathrm{G} 10500 \sim \mathrm{G} 10500>\mathrm{LA}-\mathrm{A} 97075>\mathrm{S} 30400>\mathrm{C} 26000$ $>$ A97075.

4. The increase in wear resistance of the laser-alloyed specimens is attributed to the presence of hard phases such as boro-carbides and iron aluminides, and solid solution hardened matrix.

5. The ranking of corrosion potential of various specimens in $3.5 \% \mathrm{NaCl}$ solution at $23{ }^{\circ} \mathrm{C}$ is: $\mathrm{S} 30400>\mathrm{LA}-$ $\mathrm{S} 30400>\mathrm{C} 26000>\mathrm{LA}-\mathrm{C} 26000>\mathrm{LA}-\mathrm{G} 10500>$ G10500 > LA-A97075 > A97075.

6. Except LA-C26000 and LA-G10500, the corrosion resistance of LA-S30400 and LA-A97075 in 3.5\% $\mathrm{NaCl}$ solution was deteriorated as evidenced by the increase in $\mathrm{I}_{\text {corr }}$ compared with the as-received specimens due to the existence of the phase boundaries of borocarbides and iron aluminides as the active sites for corrosion attack. In addition, galvanic effect is significant in LA-A97075 due to the presence of cracks.

7. Among the laser alloyed specimens, LA-S30400 possesses the highest wear and corrosion resistance.

\section{Acknowledgments}

The work described in this paper was fully supported by the research grants from the Fundo para o Desenvolvimento das Ciencias e da Tecnologia (Project no. FDCT 005/2008/A1) and the Research Committee of University of Macau (Project no. RG068/07-08S/KCT/FST).

\section{References}

[1] C.Y. Liu, L.Y. Yu, W. Tian, J.C. Tang, Experiments of Laser Surface Engineering for the Green Remanufacturing of Railway Coupler, Key Engineering Materials, 373-374 (2008) 354-357.

[2] F.C.J. Fellowes, W.M. Steen, 'Laser Surface Treatment' in 'Advanced Surface Coatings', Ed. D.S. Rickkerby and A. Matthews, Blackie, USA, 1991, p.244-277.

[3] L. Costa, K. Lansford, D. Rajput, W. Hofmeister, Unique Corrosion and Wear Resistant Identification Tags Via LISI ${ }^{\mathrm{TM}}$ Laser Marking, Surface and Coatings Technology, 203 (2009) 1984-1990.

[4] S. Valette, P. Steyer, L. Richard, B. Forest, C. Donnet, E. Audouard, Influence of Femtosecond Laser Marking on the Corrosion Resistance of Stainless Steels, Applied Surface Science, 252 (2006) 4696-4701.

[5] C. Tassin, F. Laroudie, M. Pons, L. Lelait, Carbidereinforced Coatings on AISI 316 L Stainless Steel by Laser Surface Alloying, Surface \& Coating Technology, 76-77 (1995) 450-455.

[6] G. Thawari, G. Sundarararjan, S.V. Joshi, Laser Surface Alloying of Medium Carbon Steel with $\mathrm{SiC}_{(\mathrm{P})}$, Thin Solid Films, 423 (2003) 41-53.

[7] C.T. Kwok, F.T. Cheng, H.C. Man, Cavitation Erosion-corrosion Behaviour of Laser Surface Alloyed AISI 1050 Mild Steel Using NiCrSiB, Materials Science \& Engineering A, 303 (2001) 250-261. 
[8] C.T. Kwok, F.T. Cheng, H.C. Man, Cavitation erosion and Corrosion Behaviors of Laser-aluminized Mild Steel, Surface \& Coating Technology, 200 (2006) 3544-3552.

[9] H.C. Man, S. Zhang, T.M. Yue, F.T. Cheng, Laser surface alloying of $\mathrm{NiCrSiB}$ on Al6061 Aluminum Alloy, Surface \& Coating Technology, 148 (2001) 136-142.

[10] K.F. Tam, F.T. Cheng, H.C. Man, Enhancement of Cavitation Erosion and Corrosion Resistance of Brass by Laser Surface Alloying with Ni-Cr-Si-B, Surface \& Coating Technology, 149 (2002) 36-44.

[11] Z. Kalincsak, J. Takacs, G. Vertesy, A. Gasparics, Local Domain Structure on the Surface of Carbon-Steels in the Vicinity of Laser Marking, Czech. J. Phys, 54(2004) D687-691.

[12] J.C. Ion, Laser Materials Processing of Engineering Materials, $1^{\text {st }}$ ed., Elsevier, Great Britain, 2005, p.152.

[13]E. Kannatey-Asibu, Jr., Principles of Laser Materials Processing, $1^{\text {st }}$ ed., Wiley, USA, 2009, p.419.

[14] J.C. Ion, Laser Materials Processing of Engineering Materials, $1^{\text {st }}$ ed., Elsevier, Great Britain, 2005, p.144.

[15] ASTM Standard G5-92: 'Standard Referemce Test Method for Making Potentiodynamic Anodic Polarization Measurement, ASTM Standards, ASTM, Philadelphia, USA.

[16] R.W. Revie, Uhlig's Corrosion Handbook, $2^{\text {nd }}$ ed., Wiley, Canada, 2000, p.142.

(Received: July 9, 2009, Accepted: December 21, 2009) 